\title{
A REFORMA DA EDUCAÇÃO PROFISSIONAL: CONSIDERAÇÕES SOBRE ALGUNS TEMAS QUE PERSISTEM
}

\author{
PROFESSIONAL EDUCATION REFORM: CONSIDERATIONS ON A FEW PERSISTING ISSUES
}

\author{
Celso João Ferretti1
}

Resumo Este artigo traz à baila dois temas provocados pelo instigante texto de Kuenzer publicado neste mesmo número. O primeiro deles diz respeito a algumas questões sobre a qualificação profissional suscitadas na parte introdutória, desdobrandose na discussão sobre a educação profissional no âmbito da produção flexível. Na abordagem de tais questões foi extensamente utilizado um artigo publicado há poucos anos pelo autor deste artigo, no qual se tratou das relações estabelecidas por parte dos educadores com a concepção relativista de qualificação profissional. O segundo tema, complementar à discussão de Kuenzer, refere-se a processos de implementação das reformas educacionais relativas ao ensino médio e à educação profissional de nível técnico, desencadeadas na década de 1990 e continuadas pelo governo Lula. Para seu desenvolvimento foram utilizados elementos referentes a duas pesquisas das quais o autor participou recentemente.

Palavras-chave reforma do ensino médio; reforma do ensino técnico; qualificação profissional.
Abstract This article brings up two issues brought about by the instigating text by Kuenzer published in this edition. The first has to do with a few matters regarding professional qualification evoked in the introduction, unfolding in the discussion on professional education in the flexible production ambit. While dealing with such issues, extensive use was made of an article published a few years ago by this article's author dealing with the relationships established by educators with the relativistic concept of professional qualification. The second theme, which complements Kuenzer's discussion, has to do with the process of implementing educational reforms regarding middle education and technical-level professional education, put into motion in the 1990's and continued by the Lula administration. Elements involved in the two surveys the author participated in recently were used to develop the article.

Keywords middle education reforms; technical education reforms; professional qualification. 


\section{Introdução}

Kuenzer produziu, no texto que é objeto de debate, uma bem articulada e fundamentada discussão sobre os rumos que a educação profissional tem seguido nas décadas de 1990 e 2000 em nosso país, optando por abordá-los da perspectiva da inclusão e exclusão dos sujeitos sociais que demandam tal aspecto de sua formação ou são a ele submetidos ao buscarem espaço no mercado de trabalho, seja sob a forma de trabalhadores assalariados, seja sob a de autônomos. A tese que orienta a discussão, baseada "nos pressupostos teórico-metodológicos do materialismo histórico" e em pesquisas empíricas realizadas "na cadeia coureiro-calçadista e em empresas reestruturadas do setor de gás, petróleo e energia", é formulada logo no início, tendo como contexto a acumulação flexível que caracterizaria a configuração atual do modo de produção capitalista no país:

“(...) do ponto de vista do mercado, ocorre um processo de exclusão da força de trabalho dos postos reestruturados, para incluí-la de forma precarizada em outros pontos da cadeia produtiva. Já do ponto de vista da educação, se estabelece um movimento contrário, dialeticamente integrado ao primeiro: por força de políticas públicas 'professadas' na direção da democratização, aumenta a inclusão em todos os pontos da cadeia2, mas precarizam-se os processos educativos, que resultam em mera oportunidade de certificação, os quais não asseguram nem inclusão, nem permanência."

A tese aponta claramente para uma articulação 'virtuosa' entre o mercado de trabalho e o sistema escolar referenciado, que imagino ser o público, mas contrária à propalada pelo discurso que justificou e justifica as reformas educacionais da década de 1990 e início da de 2000. Estas visariam, de acordo com tal discurso, a uma outra relação 'virtuosa': a inclusão qualificada de pelo menos parcela considerável da população nos postos de trabalho, denominados por Kuenzer de "reestruturados", tendo em vista as supostas necessidades do sistema produtivo, uma ficção da qual os propositores das reformas eram bem conscientes.

Um aspecto que me chama a atenção diz respeito ao desdobramento da tese em termos do "consumo flexível de competências diferenciadas, que se articulam ao longo das cadeias produtivas", constituindo "combinações [que] não seguem modelos preestabelecidos, sendo definidas e redefinidas segundo as estratégias de contratação e subcontratação" de acordo com os interesses da produção. Tal desdobramento permitiu à autora retomar, de forma criativa, a concepção relativista de qualificação profissional, ou, pelo menos, aspectos dela, dado que o que definiria a relação entre capital e trabalho, nas condições referidas, não seria a posse, por parte do trabalhador, de atributos técnicos ou pessoais em si mesmos, mas sua funcionalidade para o capital. Esta funcionali- 
dade determina, no meu entender, não 'apenas' a inclusão ou a exclusão na empresa ou em determinados setores desta, mas também outras dimensões das relações de produção (formas de contratação, salários etc.). O grifo anterior decorre de que, na minha leitura do texto, Kuenzer parece ter colocado muita ênfase em tal funcionalidade, obscurecendo a dimensão dos requisitos técnicos e pessoais que o empresário demanda para a contratação e uso da força de trabalho.

Embora concordando inteiramente com a autora a respeito de como o capital se vale da força de trabalho na atual conjuntura, o questionamento precedente me permite repor as relações não de oposição, mas de caráter dialético, entre as concepções 'substancialista' e 'relativista' da qualificação profissional abordadas em trabalho anterior (Ferreti, 2004). Considero que o enfoque da qualificação como relação social, sem abandonar o exame das relações entre a qualificação do trabalhador e as demandas da inovação tecnológica, antes tomando-a como elemento importante, confere prioridade ao exame do conceito no âmbito das relações sociais de produção e, nesse sentido, o enriquece. Sob esse ângulo, pode-se dizer que a concepção relativista incorpora a substancialista ampliando-a, conferindo maior importância à qualificação como relação social.

A 'novidade' trazida ao debate sobre a qualificação pela restruturação produtiva, apoiada na flexibilização e integração, todavia, não o é tanto assim. Na verdade, faz tão-somente pender a balança para o enfoque substancialista da qualificação, ou seja, para a concepção clássica da sociologia do trabalho. O passo à frente, neste caso, consiste em repor o debate pelo menos na perspectiva relativista. Isto implica tratar a questão de forma muito diversa da que vem sendo feita e, certamente, iluminada pela crítica à economia política e pela sociologia voltadas para o conteúdo e para o processo do trabalho no interior da fábrica, bem como para o 'construto social' produzido no âmbito dos processos de reprodução fundados no trabalho.

O enfoque substancialista fortaleceu-se na década de 1990, tanto na literatura educacional quanto na da economia, da administração de empresas, da psicologia e mesmo da sociologia, de priorização da noção de competência em detrimento do conceito de qualificação, ainda que por diferentes razões. Por outro lado, especialmente entre os educadores que adotaram uma postura crítica em relação a ela, houve muita produção dedicada ao seu desmonte. A sociologia do trabalho não cometeu, no entanto, o equívoco bastante presente nas outras áreas, de entender o conceito de qualificação e a noção de competência como sinônimos. Na área educacional, especialmente naqueles setores menos ligados aos estudos acadêmicos sobre as relações entre educação e trabalho e particularmente naqueles ligados ao ensino médio e ao ensino técnico, grassou a substituição, por sinonímia, do conceito de qualificação pela noção de competência, provavelmente por efeito dos documentos oficiais e legais de 
proposição e regulamentação das reformas nessas duas modalidades de ensino. O Ministério do Trabalho também contribuiu para tal, por intermédio de suas ações no âmbito da educação profissional de nível básico.

O conceito mais refinado de qualificação profissional (o relativista) talvez não tenha se difundido entre os educadores devido à sua complexidade e às dificuldades inerentes à sua utilização prática ou à sua incorporação como categoria analítica na pesquisa empírica. Parte dessa dificuldade decorre do fato de que não faz sentido estabelecer distinções práticas entre as concepções substancialista e relativista de qualificação profissional, pois essa distinção é apenas teórica. Quando Friedmann e Naville realizavam seus estudos não se limitavam, na prática, a estabelecer relações diretas e mecânicas entre inovações tecnológicas e qualificações, até porque nenhum deles se restringiu unicamente ao exame de como as inovações afetam o processo e a organização do trabalho fabril e mesmo dos serviços. Trata-se mais de uma questão de ênfase, a qual tende a ressaltar os efeitos do avanço do progresso técnico sobre a qualificação técnica dos trabalhadores em detrimento de outros aspectos.

Poder-se-ia considerar, por isso, que a ênfase na abordagem substancialista se deveria ao fato de que tais autores realizam o exame da qualificação no âmbito do fordismo e da estreita relação entre o posto de trabalho e o desempenho das tarefas que lhe são adstritas. Isto conferiria enorme importância às características técnicas das tarefas e, por isso, aos requisitos técnicos da força de trabalho necessários à sua realização. Uma objeção a este argumento é a de que, mesmo com a tendência à diluição dos postos de trabalho observada a partir das inovações tecnológicas e organizacionais que passam a ocorrer com a denominada reestruturação produtiva, muito da literatura recente sobre as qualificações dos trabalhadores continua a circunscrever-se ao enfoque substancialista, ainda que priorizando aspectos anteriormente pouco considerados (por exemplo, o trabalho mental e as 'qualificações sociais'). Por outro lado, no âmbito do fordismo, o posto de trabalho é elemento central para a análise em ambos os enfoques, uma vez que a partir dele se organiza a produção no período em que os autores considerados tratam da qualificação.

A discussão a partir do posto de trabalho não parece constituir, portanto, um encaminhamento adequado da questão posta anteriormente, apesar da diluição tendencial dos postos conduzir ao debate sobre as semelhanças e diferenças entre o conceito de qualificação e a noção de competência. Parece mais razoável considerar que o elemento distintivo reside no fato de que, na concepção relativista, a ênfase se desloca do plano das relações entre o avanço das forças produtivas e a adequação de um dos elementos da reprodução da força de trabalho (seu aprimoramento, como valor de uso, pela via da qualificação) para, incluindo-o, centrar-se sobre as relações de produção, o que implica, necessariamente, tratar a qualificação profissional no âmbito da correlação de forças capital-trabalho. 
Todavia, mesmo desse ponto de vista, o olhar pode ser guiado pela perspectiva da relação entre desenvolvimento tecnológico e qualificação técnica, como o faz, por exemplo, Braverman. Poder-se-ia dizer que este é o tipo de olhar que, privilegiando um aspecto importante das relações de produção, se fixa nele, produzindo uma leitura economicista dessas mesmas relações. Tal advertência não deve elidir as possibilidades descortinadas pelo enfoque relativista, como, por exemplo, as relacionadas ao exame dos critérios econômicos para a definição de sistemas classificatórios e de hierarquização de profissões.

Esse possível viés não deveria impedir ou prejudicar o desenvolvimento das potencialidades teóricas e investigativas da concepção da qualificação como relação social. Em outros termos, o conceito ampliado de qualificação derivado do enfoque relativista descortina, a nosso ver, a possibilidade de tratar a qualificação não apenas no plano econômico, mas também no político e no cultural. Por exemplo, os critérios econômicos utilizados para a definição dos sistemas classificatórios e das hierarquias poderiam ser trabalhados também a partir dos critérios sociais, culturais e ideológicos. Estes critérios não apenas matizam aqueles, mas introduzem variações nas classificações e nas suas transformações históricas, permitindo compreender como se estruturam, coletivamente, relações de trabalho que envolvem, entre outros aspectos, a definição de salários e de condições do exercício profissional, bem como as estruturas de poder no interior das organizações produtivas e destas com as organizações dos trabalhadores. Deriva dessas possibilidades a importância da concepção relativista para os educadores que se proponham a analisar as relações entre trabalho e educação tendo por referência o conceito de qualificação profissional.

Talvez residam aí a força e a fraqueza de tal concepção. A força decorre do fato de que se poderá, dessa forma, entender a qualificação como síntese de múltiplas determinações, sempre cambiante, ela própria, assim como tais determinações, e sempre inacabada, como sugere Villavicencio (1992). A fraqueza está em que, assim entendida, a investigação sobre a qualificação, se, por um lado, torna-se mais promissora e instigante, por outro, põe-se como mais complexa e mais difícil. Esta não é uma questão de somenos importância, tanto do ponto de vista teórico quanto do metodológico. No plano teórico, a concepção traz à baila a necessidade de definição de categorias explicativas, assim como de delimitações, dada a amplitude adquirida pelo conceito. No plano metodológico, as dificuldades remetem à definição de enfoques investigativos, assim como à elaboração de instrumentos suficientemente sensíveis para captar as informações necessárias. É possível que, entre outras, esta seja uma das razões pelas quais a abordagem relativista da qualificação, da qual a concepção da qualificação como relação social é tributária, tem encontrado dificuldade para se firmar. 
Outra questão suscitada pelo texto de Kuenzer diz respeito à polarização ou não das qualificações requeridas pelo capital. Concordo com sua consideração de que este desencadeou, em função da configuração que assumiu, uma demanda maior e geral por mais educação, do ponto de vista da formação do trabalhador/consumidor. Concordo, também que, apesar disso, a distribuição de educação se dá de forma desigual, tanto no que se refere ao acesso quanto à qualidade. Não interpreto tal desigualdade apenas como desídia do Estado, mas como expressão de relações de poder e dominação. Interpreto-a, ainda, como funcional ao capital, como se a educação, transformada em mercadoria, devesse ser tratada como outras mercadorias em tempo de flexibilização, ou seja, disponibilizada de forma diferenciada, segundo nichos de mercado, para consumidores diferenciados que, frente às demandas daquele, desempenhariam flexivelmente funções diferenciadas e, ao mesmo tempo, intercambiáveis.

Todavia, não estou plenamente convencido de que estejamos nos defrontando com um contexto em que a polarização das qualificações tenha sido superada. Na minha interpretação, o texto ao mesmo tempo a nega e a reforça. Nega-a, e concordo com isso, no sentido de que, de um lado, tende a diluir-se, na empresa flexibilizada, a separação entre os que pensam (os mais qualificados) e os que executam (os menos qualificados), pois uns e outros são instados ao enfrentamento compartilhado dos eventos imprevisíveis, em benefício da produtividade. De outro lado, como assevera Kuenzer, com propriedade, o capital dispõe desses trabalhadores diferentemente formados de modo que suas qualificações valham não por si mesmas, mas de acordo com os interesses dele, capital, o que lhe faculta utilizar a mão-de-obra não apenas como valor de uso, mas também como valor de troca, na perspectiva da flexibilidade qualitativa (em termos do processo de trabalho), assim como da quantitativa (em termos de desregulamentação do mercado).

A confirmação da polarização das qualificações parece-me estar presente na própria formulação da tese exposta por Kuenzer. Embora me pareça claro que a flexibilização do uso da força de trabalho implique a possibilidade, descortinada pela tese, de que trabalhadores qualificados possam ser excluídos do exercício de atividades em postos 'reestruturados', ou seja, de postos em que o trabalho é mais qualificado, e suas qualificações subutilizadas, segundo as conveniências, em postos não 'reestruturados', não me parece que a possibilidade oposta esteja dada. Isso não altera as qualificações técnicas dos trabalhadores, fruto de sua formação e de sua experiência profissional, embora, do ponto de vista da concepção relativista de qualificação, sejam elas avaliadas, pelo capital, menos por elas mesmas e mais pela sua funcionalidade.

Tal polarização pode também ser percebida nos argumentos expostos por Kuenzer no que tange à educação dos trabalhadores. Se, de um lado, a autora assevera que: 
“(...) é por meio (...) da educação geral (...), disponibilizada de forma diferenciada por origem de classe, que os que vivem do trabalho adquirem conhecimentos genéricos que lhes permitirão exercer, e aceitar, múltiplas tarefas no mercado flexibilizado. Ser multitarefa, neste caso, implica exercer trabalhos simplificados, repetitivos, fragmentados, para os quais seja suficiente um rápido treinamento, de natureza psicofísica."

De outro lado, ela aponta que,

“Para os que exercerão atividades complexas na ponta qualificada das cadeias produtivas, a educação básica é rito de passagem para a educação científico-tecnológica e sócio-histórica de alto nível (...). Ser multitarefa, neste caso, significa a capacidade de adaptar-se a múltiplas situações complexas e diferenciadas, que demanda o desenvolvimento de competências cognitivas mais sofisticadas que permitam a solução de problemas com rapidez, originalidade e confiabilidade."

Isso não invalida, absolutamente, a tese apresentada por Kuenzer quanto à flexibilização funcional dos usos dessa formação diferenciada, conforme as necessidades e demandas da produtividade, tendo em vista a acumulação do capital. Assim como não invalida o caráter relativo da influência que essa formação diferenciada exercerá na inclusão e na exclusão de trabalhadores no mercado de trabalho. Sob determinadas circunstâncias e em função dos setores produtivos considerados, a inclusão será mais fácil para os menos qualificados (por exemplo, no comércio e nos serviços menos sofisticados). Entretanto, o contrário não é necessariamente verdadeiro (como é sabido, no processo de downsizing instituído por empresas reestruturadas, vários executivos, muito bem qualificados, perderam seus empregos). A superqualificação, dependendo novamente das circunstâncias e das áreas de atividade econômica, pode contribuir mais para a exclusão do que para seu contrário.

No que tange às políticas nacionais de educação profissional, tendo a concordar com a crítica de Kuenzer à limitada contribuição que tal modalidade de ensino tem oferecido à qualificação dos trabalhadores brasileiros quando se expressa sob a forma de uma série de programas de curta duração, aligeirados e fragmentários, a maioria dos quais não articulados à formação escolar básica de longa duração. Tendo em vista a situação dramática vivida por essa parcela da população, especialmente seu contingente mais empobrecido, considero procedentes suas observações a respeito do caráter focal que tem assumido a maior parte desses programas, bem como as que se referem à tendência de a expansão da oferta destes resultar mais no deslocamento de recursos públicos para a iniciativa privada do que no aumento de oportunidades de inserção no mercado de trabalho. 
Kuenzer dedicou um pequeno espaço à discussão da educação profissional de nível técnico, dado o foco de suas preocupações. As pesquisas das quais tenho participado nos últimos anos, referentes ao ensino médio e ao ensino técnico, têm mostrado que tanto quanto os programas de educação profissional analisados por Kuenzer, as reformas relativas a tais modalidades são muito promissoras no que se refere à formação geral e profissional de qualidade. Em função do limite de espaço, apresento a seguir, sem maiores detalhes, alguns dos resultados obtidos por meio das investigações mencionadas.

No que diz respeito ao ensino médio, estudo realizado com foco em um dos aspectos centrais das reformas - o protagonismo dos alunos - em duas escolas paulistas, uma das quais oferecendo apenas ensino médio e outra, ensino fundamental e médio, e em três escolas de ensino médio de Fortaleza (Zibas, Ferretti e Tartuce, 2006), mostrou que a sustentabilidade daquelas é afetada por razões de ordem financeira, político-administrativas e pedagógicoculturais.

Do ponto de vista financeiro, o volume restrito de recursos colocados à disposição das escolas para atenderem as inúmeras demandas que lhes eram feitas em decorrência das reformas, determinou uma série de percalços para seu atendimento, tais como atraso de salários docentes; precariedade de instalações, como bibliotecas e laboratórios; colapso de alguns serviços, como telefonia; falta de recursos para a manutenção e uso de equipamentos; insuficiência de equipamentos de informática, confirmando, neste último aspecto, pesquisa de Abramovay e Castro (2003).

Da perspectiva político-administrativo, os processos verticalizados de elaboração, difusão e implementação das reformas produziram um efeito deletério sobre sua aceitação. Apesar de revestidos de formalidades democráticas, tais processos não apenas impediram ou distorceram os debates sobre o pretendido, produzindo críticas acerbas da academia, sindicatos e associações, como também fizeram com que as reformas chegassem às escolas como 'pacotes' a serem aplicados, muitas vezes justificados simplesmente como determinações (eufemisticamente, como indicações) das secretarias da Educação, mas revestidos do discurso da autonomia da unidade escolar. A diferença de contextos (em São Paulo, o autoritarismo da Secretaria da Educação; no Ceará, o carisma do secretário que capitaneou a implementação da reforma) produziu, no entanto, resultados diferentes entre professores, interferindo nas formas de adesão e resistência às proposições oficiais, ainda que, nos dois casos, as exigências legais obrigassem a obediência meramente formal ao estatuído. Da mesma forma, práticas gestionárias já instaladas, referentes ao preenchimento do cargo de direção das escolas, políticas referentes à carreira docente e aos gestores, não uniformes para os dois estados envolvidos, produziram diferenças na implementação da reforma. Um elemento comum, com fortes efeitos sobre os resultados negativos, foram as condições precárias de trabalho e os 
baixos salários que acabaram por desmotivar os professores ou por afastá-los das salas de aula.

No âmbito pedagógico-cultural, as propostas de reforma curricular - entendendo-se como tal a construção conjunta de projeto pedagógico por parte da unidade escolar, as alterações nas práticas de sala de aula, envolvendo metodologias de trabalho, uso de material didático e procedimentos de avaliação, as relações com as famílias dos alunos, as práticas interdisciplinares de planejamento e condução das atividades pedagógicas etc. - não conseguiram sensibilizar suficientemente os docentes e, às vezes, nem os próprios gestores. Várias razões podem ter concorrido para tal. Entre elas avulta, de um lado, a ausência ou pouco conhecimento da reforma como projeto político-cultural, ou, ainda, o conhecimento 'pedagogicamente filtrado' deste. De outro, fazemse presentes razões que reportam à vida institucional e à cultura da escola, tais como condições de trabalho precárias ou pouco estimulantes, cumprimento de normas muitas vezes rígidas, gerando a necessidade de dar resposta às inúmeras solicitações, quer burocráticas, quer pedagógicas, dos órgãos gestores. Sob esse mesmo aspecto, parece haver esforços por parte dos docentes no sentido de preservar sua autonomia e poder relativos e, por isso, a recusa às determinações de gestores internos e externos à unidade escolar.

Finalmente, foram detectadas dificuldades da escola em incorporar às práticas pedagógicas as mudanças radicais indicadas pela reforma, entre as quais avulta o destaque conferido ao protagonismo juvenil e à necessidade inerente de contemplar as peculiaridades da cultura juvenil, numa instituição que tende a tratar os jovens não como tais, mas principalmente como estudantes. Esse conjunto enorme de interferências acabou por produzir aproximações diversas dos professores com a reforma que variaram de sua recusa pura e simples à adesão maior ou menor, passando pela dissimulação traduzida em adesão formal e indiferença ou recusa real. A crítica de caráter políticoideológico se fez presente, mas de forma esporádica e limitada.

No que se refere ao ensino técnico, a investigação, que teve por objetivo central verificar como uma unidade escolar se apropriou da reforma referente a essa modalidade da educação profissional e a implementou (Silva Jr. e Ferretti, 2006), foi realizada junto a uma escola técnica pública, localizada em cidade do interior de São Paulo, cujas origens situam-se na década de 1920. A unidade escolar, por pertencer, desde os anos iniciais da década de 1980, a uma rede de ensino pública, orienta-se, no geral, por indicações e determinações decorrentes dessa condição. No entanto, a pesquisa baseou-se no pressuposto de que, apesar disso, haveria certo espaço para que sua tradição, história e cultura se fizessem presentes no processo de implementação da reforma.

A rede e, portanto, a escola passaram por dois momentos recentes de mudança, tendo em vista as perspectivas de reestruturação do ensino técnico. 
O primeiro, que ocorreu antes mesmo da promulgação do decreto 2.208/97, foi analisado por Oliveira (1998). O segundo, sobre o qual se deteve a pesquisa realizada, foi desencadeado de forma centralizada pela Coordenadoria Técnica da rede a partir de 2000, tendo como referência os documentos orientadores da reforma. Para tal, a referida coordenadoria montou um esquema de supervisão, capacitação e avaliação que lhe permitiu interferir diretamente na implementação da reforma, a qual enfrentou vários percalços, de tal forma que, cinco anos após seu início, os professores da escola investigada encontravam sérias dificuldades para colocar em prática o modelo pedagógico assentado nas competências. Embora a escola mantenha também o ensino médio, que foi pesquisado, o estudo centrou-se mais no ensino técnico.

De forma bastante resumida apresentam-se, na seqüência, alguns aspectos mais centrais que avultaram no processo de investigação, tais como o conhecimento detido pelos professores a respeito dos documentos orientadores da reforma, a preparação destes para trabalhar de acordo com o prescrito pela rede e, por conseqüência, as dificuldades encontradas para fazê-lo e, finalmente, a relação estabelecida por eles entre a reforma e a qualidade do ensino que a escola vem oferecendo.

$\mathrm{O}$ acesso dos professores aos documentos da reforma, especialmente aqueles que implicariam um conhecimento relativamente sólido a respeito dos objetivos e fundamentos da reforma, assim como das propostas de estrutura curricular correspondente, foi parco ou inexistiu. As informações divulgadas revestiram-se de caráter operacional. Foram transmitidas ou por 'professores multiplicadores' (usualmente os coordenadores de curso) ou por documentos internos emitidos pela Coordenadoria Técnica. Em função disso, verificou-se que a maioria dos entrevistados (inclusive coordenadores) tinha, a respeito da reforma e do seu sentido político-ideológico, uma visão próxima do senso comum.

As 'capacitações' oferecidas pela rede foram vistas pelos professores como esporádicas e pouco contributivas para o enfrentamento dos desafios pedagógicos postos pela reforma. Além disso, consideraram precária a fórmula do 'professor multiplicador' para sua 'capacitação', ou porque este enfrentava, ele próprio, dificuldades para compreender as demandas que lhe eram feitas no plano pedagógico, ou porque as condições objetivas para encontrar-se com os colegas a fim de discutir as orientações eram adversas. Tal circunstância, comum nas escolas, era agravada pelo fato de que vários dos docentes, originários de outras áreas profissionais, desempenhavam atividades em empresas, como sói acontecer nas escolas técnicas. Por 'estarem professores', conforme a expressão reiterada inúmeras vezes, não era raro sentirem dificuldade para relacionar-se com as demandas e com o jargão educacional, apesar de vários terem passado pelos cursos de Esquema I, cuja finalidade seria exatamente a de inseri-los nesse campo. 
Os professores encontraram problemas para trabalhar de acordo com a proposta da rede, que prioriza o desenvolvimento de competências. O primeiro diz respeito ao domínio da noção, seja pela polissemia do termo, seja pela insistência da rede na sua compreensão teórica, seja para compreender as diferenças e associações com o conceito de habilidade. O segundo, decorrente do primeiro, expressou-se na tentativa, quase sempre frustrada, de utilizar a noção pedagogicamente. Ciente dessa dificuldade e também por acreditar que os professores assimilariam mais facilmente tal transposição por outros meios, que não a discussão e o debate, a coordenação técnica da rede produziu um formulário de plano de trabalho a ser preenchido pelos docentes para cada aula ou conjunto de aulas de uma dada unidade didática, segundo a nomenclatura ligada à 'formação' por competência. Daí resultaram várias conseqüências: enorme tempo consumido no preenchimento do formulário, mal-estar e contrariedade entre os professores e, finalmente, dissimulação, dado que os professores passaram a preencher os planos segundo as recomendações, mas desenvolviam as aulas de acordo com a tradição do ensino técnico - ênfase no desenvolvimento expositivo das aulas, nas formas de avaliação cultivadas ao longo do tempo etc. - embora 'adornadas' com a utilização da internet, da informática, de visitas, de sessões de apresentação coletiva de trabalhos e outros procedimentos semelhantes.

A relação entre a reforma do ensino técnico e a qualidade da educação oferecida pela escola foi encarada pelos professores, em geral, a partir dos efeitos desta sobre a duração dos cursos. Segundo eles, um dos efeitos deletérios da reforma consistiu na redução da duração de seis para três semestres, promovendo o aligeiramento do ensino ofertado e, em conseqüência, a precarização da formação dos alunos tendo em vista a demanda das empresas. Tal avaliação já havia sido detectada por Oliveira (1998), posto que o elemento central do primeiro momento da mudança consistiu na modularização do curso e sua redução, situação que permanece até o presente. Esta avaliação redunda do fato de que os professores consideram que a redução do tempo impedeos de desenvolver todo o conteúdo de suas disciplinas ou os obriga a fazê-lo às carreiras. Por outro lado, há clareza entre eles das conseqüências trabalhistas de tal redução.

Em suma, ocorreu, no geral, mas não de forma homogênea, um processo de distanciamento das propostas educacionais contidas nos documentos oficiais, não por recusa crítico-ideológica do conteúdo político e educacional deles. No meu entender, tal distanciamento decorreu, primeiro, das dificuldades encontradas pelos professores para entender e objetivar o proposto em suas práticas docentes; segundo, do privilégio conferido a um longo processo histórico de construção cultural sobre o ensino técnico, seus objetivos e suas relações com os setores para os quais os alunos devem ser preparados. O curioso é que, sem terem noção clara disso, os professores tenderam a se afi- 
nar, pelo menos na intenção, com um dos aspectos privilegiados pela reforma, em outro diapasão. Tal aspecto diz respeito à estreita relação entre progresso técnico, qualificação do trabalho e qualificação do trabalhador. Em outros termos, tenderam a se afinar com a concepção substancialista de qualificação profissional, tanto quanto o fizeram os documentos da reforma, mas em registros diferentes.

\section{Notas}

1 Professor Titular da Universidade de Sorocaba, Sorocaba, Brasil. Doutor em Educação: História, Política, Sociedade pela Pontifícia Universidade Católica de São Paulo. $<$ cferretti@fcc.org.br>

Correspondência: Rua das Rosas, 591, Jardim Haras Bela Vista, Vargem Grande Paulista, São Paulo, Brasil, CEP 06730-000.

2 Penso que cabe aqui uma observação: a expressão 'cadeia' para designar um continuum é mais adequada quando a referência é uma determinada forma de estruturação do campo do trabalho industrial, as cadeias produtivas. No caso da escola, parece-me que seria mais apropriada a expressão 'sistema de ensino', tendo em vista a mesma idéia de continuum, mas aqui de caráter escolar.

\section{Referências}

ABRAMOVAY, Míriam; CASTRO, Mary Garcia. Ensino médio: múltiplas vozes. Brasília: Ministério da Educação/Unesco, 2003.

FERRETTI, Celso João. Considerações sobre a apropriação das noções de qualificação profissional pelos estudos a respeito das relações entre trabalho e educação. Educação \& Sociedade, Campinas, v. 25, n. 87, p. 401422, 2004.

OLIVEIRA, Maria Rita Neto Sales. A prática pedagógica no ensino tecnológico: o discurso de sujeitos da escola, 1998. Mimeografado.

SILVA JR., João dos Reis; FERRETTI, Celso João. Competências e prática social: o trabalho como organizador e estruturador das reformas educacionais brasileiras no ensino médio e na educação profissional de nível técnico e sua concretização nas instituições escolares nos primeiros anos do século XXI. Relatório de pesquisa. Mimeografado.

VILLAVICENCIO, Daniel. Por una definición de la calificación de los trabajadores. In: CONGRESSO ESPANHOL DE SOCIOLOGÍA, 4, 1992, Madri.

ZIBAS, Dagmar M. L.; FERRETTI, Celso J.; TARTUCE, Gisela Lobo B. P. A reforma do ensino médio e o protagonismo de alunos e pais. In: VITAR, Ana et al. (Orgs.). Gestão de inovações no ensino médio: Argentina, Brasil e Espanha. Brasília: Liber Livro, 2006. p. 83-138. 